\title{
Ventral Hippocampal Muscimol Disrupts Context-Specific Fear Memory Retrieval After Extinction in Rats
}

\author{
Jennifer A. Hobin, ${ }^{1}$ Jinzhao $\mathrm{Ji}^{1}{ }^{1}$ and Stephen Maren ${ }^{1,2 *}$
}

\begin{abstract}
Research aimed at understanding Pavlovian fear memory extinction has yielded considerable insight into the conditions under which fear memories may become inhibited. After extinction, Pavlovian fear memory retrieval is context-specific. Fear memories are not expressed in the extinction context, but they are expressed in every other context. Research indicates that the dorsal hippocampus mediates the context-specific expression of fear memory, but the role of the ventral hippocampus in mediating this process is unknown. Insofar as the ventral hippocampus is involved in the acquisition and expression of both context and tone fear, we asked whether GABA systems in the ventral hippocampus mediate context-specific fear memory retrieval after extinction. Experiment 1 showed that ventral hippocampal inactivation with muscimol disrupted context-specific fear memory retrieval. Experiment 2 showed that rats infused with muscimol can discriminate a context in which they were shocked from a neutral context. Nonetheless, they do appear to have a mild impairment in this task. Experiment 3 showed that ventral hippocampal muscimol did not disrupt locomotor activity, but did result in a slight increase in freezing and grooming, an effect that cannot explain the context-specific retrieval deficit demonstrated in experiment 1 . These data are consistent with a role for the ventral hippocampus in mediating context-specific fear memory retrieval. $\odot 2005$ Wiley-Liss, Inc.
\end{abstract}

KEY WORDS: context-specific expression; muscimol; Pavlovian fear conditioning; reversible inactivation; renewal

\section{INTRODUCTION}

Many human fear and anxiety disorders are characterized by an inability to inhibit inappropriate fear responses (Bouton et al., 2001). Understanding the mechanisms that regulate fear memory retrieval has important implications for the treatment of these disorders. Pavlovian fear conditioning is an ideal model system for studying fear memory retrieval insofar, as it is a robust, lasting, and easily-induced form of emotional memory. Fear conditioning occurs when a neutral conditional stimulus (CS), such as a tone, is paired with a biologically relevant unconditional stimulus (US), such as a shock. After just a single pairing of these stimuli, animals will show conditional responses (CRs), such as freezing, when the CS is presented alone.

\footnotetext{
${ }^{1}$ Department of Psychology, University of Michigan, Ann Arbor, Michigan; ${ }^{2}$ Department of Neuroscience Program, University of Michigan, Ann Arbor, Michigan Grant sponsor: NIMH Grant number: R01MH065961.

*Correspondence to: Stephen Maren, Department of Psychology, University of Michigan, 530 Church Street, Ann Arbor, MI 48109-1043.

E-mail: maren@umich.edu

Accepted for publication 27 September 2005

DOI 10.1002/hipo.20144

Published online in Wiley InterScience (www.interscience.wiley.com).
}

Pavlovian fear conditioning is not context-specific; a CS will elicit a CR in any context in which it is presented. Extinction, however, renders the expression of memory for the CS context-specific. After repeatedly presenting a CS in the absence of a US, the CS will elicit greater conditional responding outside the extinction context when compared with inside the extinction context (Bouton and Bolles, 1979; Harris et al., 2000; Corcoran and Maren, 2001). This phenomenon, known as renewal, is dependent upon the dorsal hippocampus (Holt and Maren, 1999; Corcoran and Maren, 2001, 2004; Ji and Maren, 2005; Corcoran et al., in press). In particular, Corcoran and Maren (2004) argue that context-specific fear memory retrieval is dorsal hippocampus-dependent when the test context is ambiguous with regard to the meaning of the CS. Under these circumstances, dorsal hippocampal inactivation with the GABA agonist muscimol attenuates conditional responding both inside and outside of the extinction context (Corcoran and Maren, 2001, 2004).

To date, much of the research examining the role of the hippocampus in learning and memory processes has focused on the dorsal rather than the ventral hippocampus (Sutherland and Rudy, 1989; O'Reilly and Rudy, 2001; Rudy et al., 2002). Yet, behavioral and anatomical data suggest that the ventral hippocampus may mediate context-specific fear memory retrieval. For example, ventral hippocampal lesions disrupt the acquisition (Maren, 1999; Richmond et al., 1999; Maren and Holt, 2004; Trivedi and Coover, 2004) and expression (Maren, 1999; Richmond et al., 1999; Maren and Holt, 2004; Trivedi and Coover, 2004) of fear to a tone CS as well as the acquisition (Maren, 1999; Richmond et al., 1999) and expression (Maren, 1999; Richmond et al., 1999; Trivedi and Coover, 2004) of contextual fear. While Ferbinteanu and McDonald (2000) failed to demonstrate an effect of ventral hippocampal lesions on the acquisition of a contextual discrimination, they found that ventral hippocampal lesions prevented animals from developing a preference for a safe environment as compared with an environment in which they were shocked. Additionally, infusion of tetrodotoxin (Bast et al., 2001) and NMDA (Zhang et al., 2001) into the ventral hippocampus disrupts the acquisition of fear to contexts and tones, while the noncompetitive NMDA receptor antagonist MK-801 (Zhang et al., 2001) and the GABA agonist muscimol (Bast et al., 2001) result in context fear deficits. Ventral hippocam- 
pal muscimol also disrupts auditory fear acquisition (but see Bast et al., 2001), yet has no effect on context or auditory fear expression (Maren and Holt, 2004).

Anatomically, the ventral hippocampus has extensive reciprocal connections with the amygdala (Pitkanen et al., 2000) and the majority of projections from the hippocampus to the amygdaloid nuclei derive from the ventral hippocampus rather than the dorsal hippocampus (reviewed by Pitkanen, 2000). Data also show that lesions of ventral hippocampal efferents to the amygdala prevent contextual fear conditioning (Maren and Fanselow, 1995), suggesting that ventral hippocampus-amygdala interactions mediate this form of learning. The relationship between the ventral hippocampus and the amygdala is important, as there is wide consensus that the amygdala mediates fear learning and memory (LeDoux, 2000; Davis and Whalen, 2001; Maren, 2001). Moreover, the amygdala is involved in fear memory extinction (Davis et al., 2003; Quirk and Gehlert, 2003; Maren and Quirk, 2004) and we have data showing that lateral amygdala neurons show context-specific spike firing to CSs after extinction (Hobin et al., 2003). Collectively, these data suggest that the ventral hippocampus has a role in both contextual and auditory fear conditioning, but it is not known whether the ventral hippocampus is involved in contextual memory retrieval. We performed three experiments to examine this question. In experiment 1 , we infused rats with muscimol or saline in the ventral hippocampus and examined conditional responding to an extinguished CS either inside or outside the extinction context. In experiment 2, we examined whether ventral hippocampal muscimol disrupted rats' ability to discriminate a context in which they were shocked from a neutral context. In experiment 3 , we examined whether ventral hippocampal muscimol produced unconditional freezing or abnormal levels of activity and habituation to a novel context.

\section{MATERIALS AND METHODS}

\section{Experiment 1: Does Ventral Hippocampal Muscimol Disrupt Context-Specific Retrieval?}

\section{Subjects and surgery}

Forty-eight male Long-Evans rats (Blue Spruce) provided by a commercial supplier (Harlan Sprague-Dawley, Indianapolis, IN) and weighing between 175 and $274 \mathrm{~g}$ upon arrival were used for this experiment. Rats were housed in hanging, plastic cages and provided with food and water ad libitum. After housing, rats were handled for at least 4 days prior to surgery. Rats were anesthetized with sodium pentobarbital $(\sim 65 \mathrm{mg} / \mathrm{kg})$ and implanted bilaterally with guide cannulae (26 gauge; Plastics One, Roanoke, VA) aimed at the ventral hippocampus $(5.0 \mathrm{~mm}$ lateral to bregma; $6.3 \mathrm{~mm}$ posterior to bregma; $5.0 \mathrm{~mm}$ ventral to dura). The cannulae were affixed to the skull using jewelers' screws and dental acrylic. Thereafter, dummy cannulae (33 gauge; Plastics One) were inserted into the guide cannulae to prevent them from clogging. Animals were allowed to recover at least 4 days between surgery and testing. During this time, the dummy cannulae were changed at least three times in an effort to keep the guide cannulae clear and to habituate rats to the handling that would later be associated with intracranial infusions.

\section{Behavioral apparatus}

All fear conditioning, extinction, and testing took place in a single room in standard rodent conditioning chambers. The chambers rested on load cell platforms that were used to measure chamber displacement in response to rats' motor activity. Load-cell output was acquired and digitized on-line at $5 \mathrm{~Hz}$ using Threshold Activity software (Med-Associates, St. Albans, VT). Distinct environmental contexts (A and B) were created through the manipulation of visual, auditory, and olfactory cues in and near the conditioning room and chambers. The boxes used to transport the rats also differed from context A to B.

Infusions were made via 33-gauge internal cannulae (Plastics One). The internal cannulae were attached to $10-\mu \mathrm{l}$ syringes via polyethylene tubing (PE-20; Small Parts, Inc.) that had been back-filled with water. The syringes were mounted in infusion pumps (Harvard Apparatus, South Natick, MA) that were used to deliver the microinjections.

\section{Procedure}

Rats tested in the extinction inconsistent condition (INCON) were trained, extinguished, and tested in an $A A B$ renewal paradigm, wherein training, extinction, and testing occurred in contexts A, A, and B, respectively. Rats tested in the extinction consistent $(\mathrm{CON})$ condition were trained, extinguished, and tested in contexts ABB. Upon recovery from surgery, rats were transported to the fear conditioning room in squads of eight (context A) and placed in the conditioning chambers. After $3 \mathrm{~min}$, they received five tone $(10 \mathrm{~s}, 80 \mathrm{~dB}$, $2 \mathrm{kHz}$ )-shock ( $1 \mathrm{~mA}, 1 \mathrm{~s})$ pairings (1 min ITI). They were returned to their home cages $\sim 1$ minute after the last tone. The following day, rats were transported back to the conditioning room for extinction and equilibration sessions, which were conducted at least $1 \mathrm{~h}$ apart. Extinction was conducted in context A (INCON group) or B (CON group) and equilibration was conducted in the context opposite the extinction context. During the extinction session, rats received 45 CS-alone presentations beginning $3 \mathrm{~min}$ after placement into the chamber (1 min ITI). Rats were returned to their home cages $\sim 1 \mathrm{~min}$ after the last CS. During the equilibration session, rats were placed in the conditioning chambers for $55.5 \mathrm{~min}$ (the duration of the extinction session) before being returned to their home cages. No tones or shocks were delivered during this time.

The following day, rats were individually placed in 5-gallon buckets lined with bedding and transported in squads of four to the infusion room. Their dummy cannulae were removed and the internal infusion cannulae were inserted into the guide cannulae. Once the infusion cannulae were in place, rats were infused with sterile saline solution $(0.9 \%)$ or muscimol $(1 \mathrm{mg} / \mathrm{ml})$ at a rate of $0.16 \mu \mathrm{l} / \mathrm{min}$ for $94 \mathrm{~s}$ for a total infusion volume of $0.25 \mu \mathrm{l} /$ hemisphere. After the pumps were turned off, the infusion cannulae were left in place for $1 \mathrm{~min}$ to allow for the 
diffusion of the drug away from the cannulae tips. Thereafter, dummy cannulae were replaced when possible and rats were returned to their home cages.

Twenty minutes after replacement of the dummy cannulae, rats were transported to the conditioning room for testing. All testing was conducted in context B and consisted of 10 CS-alone presentations beginning $3 \mathrm{~min}$ after placement into the conditioning chamber (1 min ITI). Rats were returned to their home cages $1 \mathrm{~min}$ after the last tone. Hence, some rats were tested under saline in an extinction consistent $(\mathrm{CON} ; n=15)$ or an extinction inconsistent (INCON; $n=14$ ) context and some rats were tested under muscimol in an extinction consistent $(n=9)$ or an inconsistent context $(n=10)$. Conditional freezing, a measure of conditional fear, was measured during all phases of the experiment. Context was counterbalanced such that there were four possible context-configurations for training, extinction, and testing: $\mathrm{AAB}$ or $\mathrm{BBA}(\mathrm{INCON})$ and $\mathrm{ABB}$ or $\mathrm{BAA}(\mathrm{CON})$. All of the research reported in this manuscript was conducted under adherence to the NIH guidelines for animal research.

\section{Histology}

Upon completion of the experiment, animals were overdosed with sodium pentobarbital and perfused across the heart with physiological saline solution and then with a $10 \%$ formalin solution. Brains were removed and placed in a $10 \%$ formalin solution. No sooner than $6 \mathrm{~h}$ later, they were transferred to a $10 \%$ formalin-30\% sucrose solution until sectioning. Brains were sectioned (40-45 $\mu \mathrm{m})$, mounted on microscope slides, and stained with $0.25 \%$ thionin to verify cannulae placement.

\section{Data analysis}

Raw voltage scores produced by load cell displacement were sampled every $200 \mathrm{~ms}$ with Threshold Activity software and transformed into a measure of freezing. Freezing bouts were classified by five consecutive voltage scores (1 s bouts) below a predetermined threshold that has been shown to yield similar results to hand scoring. Freezing data were transformed to a percentage of total observations for each minute and those percentages were analyzed using analysis of variance (ANOVA). Post hoc comparisons were made using Fisher's PLSD $(P<0.05)$.

\section{Experiment 2: Does Ventral Hippocampal Muscimol Disrupt Context Discrimination?}

\section{Subjects and surgery}

Twenty-five male Long-Evans rats (Blue Spruce) weighing between 200 and $220 \mathrm{~g}$ upon arrival were used in the experiment. They were obtained, housed, handled, and implanted with bilateral guide cannulae aimed at the ventral hippocampus as described in experiment 1 .

\section{Behavioral apparatus}

All training and testing took place in the same fear conditioning chambers as described in experiment 1 and infusions were delivered in the same manner.

\section{Procedure}

At least 4 days after surgery, animals were transported to the fear conditioning room and pre-exposed to the conditioning chambers for $30 \mathrm{~min}$. For half of the animals, the conditioning chambers and room were configured for context $\mathrm{A}$ and for the other half they were configured for context B. Animals were returned to their home cages at the end of the session. No less than $1 \mathrm{~h}$ later, they were returned to the conditioning room and pre-exposed to the opposite context for $30 \mathrm{~min}$. They were returned to their home cages thereafter.

On day 2, rats were returned to conditioning chambers where they received contextual fear conditioning or habituation to the conditioning chamber in contexts A or B. Fear conditioning consisted of five unsignaled shocks $(1 \mathrm{~s} ; 1 \mathrm{~mA} ; 1 \mathrm{~min}$ ITI). One minute after the last shock, they were returned to their home cages. During habituation, rats were exposed to the conditioning chambers, but did not receive any shocks. Conditioning and habituation sessions lasted $8 \mathrm{~min}$. No less than $1 \mathrm{~h}$ later, rats were transported back to the fear conditioning room. Those rats that had been fear conditioned previously were habituated to the conditioning chambers in the opposite context; those habituated to the chambers previously were fear conditioned in the opposite context. Rats were returned to their home cages at the end of the session.

On day 3, rats were transported to the infusion room and infused bilaterally with muscimol $(1 \mathrm{mg} / \mathrm{ml} ; n=11)$ or sterile saline $(0.9 \% ; n=14)$ at a rate of $0.16 \mu \mathrm{l} / \mathrm{min}$ for $94 \mathrm{~s}$ for a total infusion volume of $0.25 \mu \mathrm{l} / \mathrm{hemisphere.} \mathrm{Infusions} \mathrm{were}$ administered as described in experiment 1 . Approximately 20 min after all rats had their dummy cannulae replaced, they were transported back to the fear conditioning room and tested for contextual fear either in the conditioning context or in the habituation context. The test session consisted of a $10 \mathrm{~min}$ exposure to the relevant context. Rats were returned to their home cages at the end of the session. The following day, rats received the same infusion and testing treatment with the exception that they were tested in the opposite context. Hence, all rats were tested in both the shock and habituation contexts after either saline or muscimol infusion. Importantly, the test context order was counterbalanced.

\section{Histology}

Histology was conducted as in experiment 1.

\section{Data analysis}

Data analysis was conducted as in experiment 1.

\section{Experiment 3: Does Ventral Hippocampal Muscimol Disrupt Unconditional Freezing and Habituation to a Novel Environment?}

\section{Subjects and surgery}

Fifteen male Long-Evans rats (Blue Spruce) weighing between 175 and $199 \mathrm{~g}$ upon arrival were used for this experi- 
ment. Subjects were acquired, housed, handled, and implanted with bilateral guide cannulae aimed at the ventral hippocampus as described in experiment 1 .

\section{Behavioral apparatus}

All testing took place in the fear conditioning chambers described in experiment 1 and infusions were delivered in the same manner.

\section{Procedure}

On each of 3 consecutive days, animals were transported to the infusion room and infused with muscimol $(1 \mathrm{mg} / \mathrm{ml}$; $0.5 \mu \mathrm{g} /$ hemisphere; $n=7)$ or saline $(0.9 \% ; n=8)$. Infusions were delivered at a rate of $0.25 \mu \mathrm{l} / \mathrm{min}$ for $94 \mathrm{~s}$ for a total infusion volume of $0.5 \mu \mathrm{l} /$ hemisphere (note that this is twice the dose of muscimol used in experiments 1 and 2). Approximately 20 min after their dummy cannulae were replaced, rats were transported to the fear conditioning room and placed in the fear conditioning chambers (context A) for $10 \mathrm{~min}$. Rats did not receive any tones or shocks during this time. All sessions were videotaped for off-line analysis of rearing, grooming, and chamber crossovers.

\section{Data analysis}

Conditional freezing was measured as in experiment 1 . Crossovers, another measure of locomotor activity, were scored each time a rat's front and back paws crossed the center of the chamber. The center-line was drawn from the front to the back of the chamber, thus dividing the chamber into left and right halves. Rearing and grooming were each sampled every $6 \mathrm{~s}$ for a total of 10 observations per minute. Rats were reared when they were standing on their hind paws. It was possible for rats to be reared and frozen simultaneously. Grooming was scored if rats were not in a rearing position and were cleaning themselves with their mouths or paws. The percentage of time spent performing each behavior during each minute of the session was recorded. All data were analyzed using ANOVA, and post hoc tests were conducted using Fisher's PLSD $(P<0.05)$.

\section{RESULTS}

\section{Experiment 1: Ventral Hippocampal Inactivation Disrupts Context-Specific Retrieval}

Muscimol animals with cannulae bilaterally in the ventral hippocampus and saline animals regardless of placement were included in the results (Fig. 1). Conditional freezing during the entire training (left panel) and extinction (right panel) sessions is shown in Figure 2. During training, INCON and CON rats exhibited similar levels of freezing, and showed increases in freezing as the conditioning session progressed. These data were confirmed by a significant effect of minute $\left(F_{(7,371)}=127.4\right.$; $P<0.0001)$. During the extinction session, rats extinguished in the conditioning context (INCON; AAB/BBA) showed greater

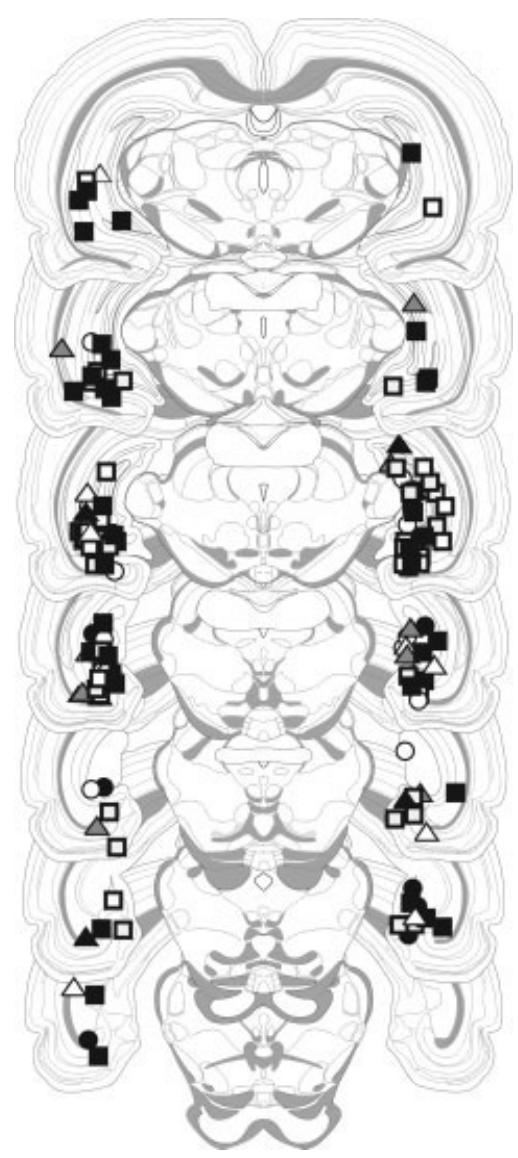

FIGURE 1. Representative cannula placements in ventral hippocampus for experiments 1 (squares), 2 (circles), and 3 (triangles) for animals receiving either muscimol (black) or saline (white) infusions. Schematic brain section images are displayed from most rostral to most caudal. Images were adapted from Swanson (1992).

pre-tone and tone freezing when compared with rats extinguished in a different context from the training context $(\mathrm{CON}$; ABB/BAA). Nonetheless, both groups of rats showed a decrease in conditional responding consistent with extinction performance and the rate of extinction for the two groups was similar. These observations were confirmed by a significant effect of group $\left(F_{(1,53)}=4.2 ; P<0.05\right)$ and a significant effect of minute $\left(F_{(47,2491)}=37.4 ; P<0.0001\right)$, but no interaction between group and minute $\left(F_{(47,2491)}=1.0 ; P=0.38\right)$.

To examine the effect of ventral hippocampal muscimol on the context-specific expression of fear, we compared average freezing during the last five extinction trials to average test session freezing (post tone minutes one through 10 minus the pre-tone baseline) for rats in each of the four groups (Fig. 3). A three-way ANOVA performed on these data reveal a significant interaction between test period, test context, and drug $\left(F_{(1,51)}=6.5 ; P<0.02\right)$. As expected, post hoc comparisons $(P<0.05)$ showed that during the test session, the SAL-INCON group froze more than the SAL$\mathrm{CON}$ group. Importantly, there was no difference between the MUS-CON and MUS-INCON groups. The SAL-INCON group also demonstrated an increase in freezing from the end of extinction to the test session. This effect was not observed in the SAL- 


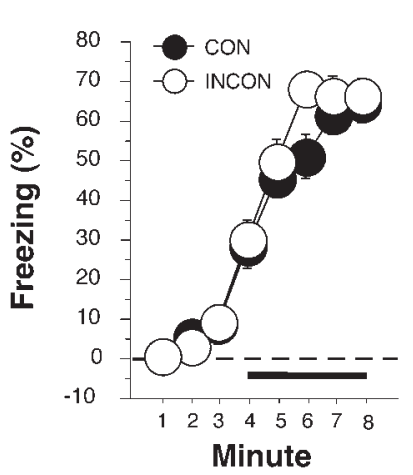

FIGURE 2. Conditional freezing during training (left) and extinction (right) for rats tested in the INCON and CON contexts in experiment 1. During training, five tone-shock pairings began 3 min after CS onset $(1 \mathrm{~min}$ ITI) and INCON and CON rats showed similar levels of freezing. During extinction, INCON rats showed greater conditional freezing during the pre-CS and CS periods when compared with CON rats, as the INCON rats were extinguished in the conditioning context. Nonetheless, CON and INCON rats had similar rates of extinction. CS onset began $3 \mathrm{~min}$ after placement into the chamber and continued for 45 trials (1 min ITI). Black bars indicate CS trials.
CON group or in the MUS-CON or MUS-INCON groups. Thus, rats treated with saline exhibited renewal of fear when the extinguished CS was presented outside the extinction context and ventral hippocampal muscimol infusions eliminated this effect.

\section{Experiment 2: Ventral Hippocampal Inactivation Results in a Mild Disruption of Context Discrimination}

Muscimol animals with cannulae bilaterally in the ventral hippocampus and saline animals regardless of placement were included in the results (Fig. 1). The effect of ventral hippocampal inactivation on the ability of rats to discriminate a context in which they were shocked from one in which they were habi-

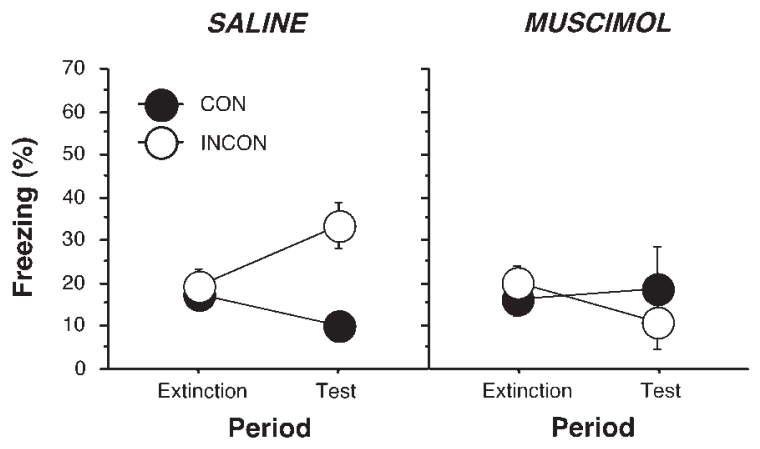

FIGURE 3. Effect of muscimol on average conditional freezing during the last five extinction trials and during the retrieval test in experiment 1. Test freezing is represented by the average freezing during minutes one through 10 minus baseline freezing. After saline infusion into the ventral hippocampus, rats tested in the INCON context froze more than the rats tested in the CON context (renewal). Muscimol infusion resulted in equivalent levels of freezing in the CON and INCON contexts. Saline rats tested in the INCON context also showed an increase in freezing from the extinction to the test period. This enhancement was not observed in the saline CON or muscimol CON or INCON groups. tuated was examined by computing a ratio of shock context freezing to total freezing [SHOCK/(SHOCK $+\mathrm{HAB})]$ for the first $4 \mathrm{~min}$ of each test session. A score of 1.0 indicates perfect discrimination between the two contexts and a score of 0.5 indicates no discrimination. As shown in Figure 4, rats tested after saline or muscimol infusion freeze more in the shock when compared with the habituation context as indicated by a discrimination ratio significantly greater than 0.5 . These observations are confirmed by one-sample $t$-tests performed on the saline $\left(t_{(1,13)}=7.7 ; P<0.001\right)$ and muscimol $\left(t_{(1,10)}=1.8 ; P\right.$ $<0.05)$ groups. Notably, discrimination under saline appears to be more robust than discrimination under muscimol; however, this difference was not statistically significant as demonstrated by an ANOVA performed on the two groups $\left(F_{(1,23)}=\right.$ 3.1; $P=0.09)$. Thus, ventral hippocampal muscimol infusions

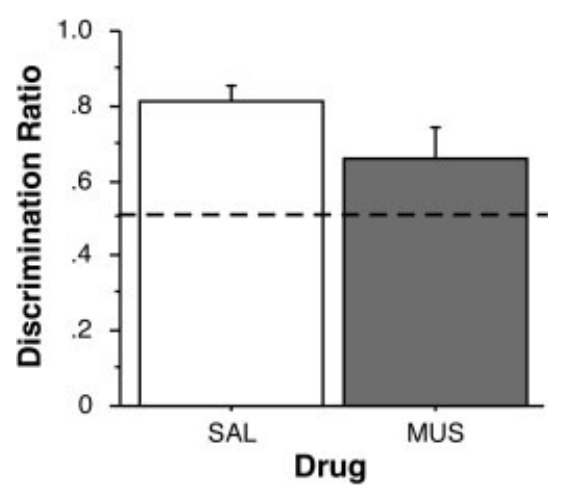

FIGURE 4. Effect of muscimol on context discrimination in experiment 2. The discrimination ratio reflects freezing in the shock context relative to total freezing in the shock and habituation contexts. A value of 1.0 indicates perfect discrimination and a value of 0.5 (dashed line) indicates no discrimination. Rats infused with saline and muscimol showed significant context discrimination. There was no difference in discrimination between the saline and muscimol animals. 


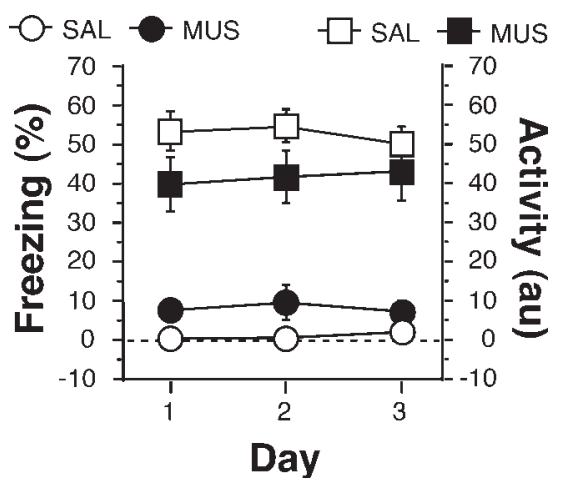

FIGURE 5. Average locomotor activity (squares) and conditional freezing (circles) on each test day in experiment 3. Locomotor activity was measured by load cell displacement in arbitrary units (au). Muscimol did not disrupt locomotor activity on any day or habituation of locomotor activity across days. Rats infused with muscimol showed greater conditional freezing on days 1 and 2 when compared with rats infused with saline.

do not significantly impair the expression of a contextual discrimination (see also Ferbinteanu and McDonald, 2000).

\section{Experiment 3: Ventral Hippocampal Inactivation Does Not Disrupt Unconditional Locomotor Activity or Habituation to a Novel Environment}

Muscimol animals with cannulae bilaterally in the ventral hippocampus and saline animals regardless of placement were included in the results (Fig. 1). Locomotor activity was averaged across the entire test session for each day and repeatedmeasures ANOVA was performed on the average scores for each of the 3 days (Fig. 5). These data show that inactivation of the ventral hippocampus with muscimol had no effect on unconditional locomotor activity $\left(F_{(1,13)}=2.0 ; P=0.18\right)$. Freezing behavior was examined in the same manner (Fig. 5). The ANOVA yielded a main effect of drug $\left(F_{(1,13)}=9.2 ; P<\right.$ 0.01 ) and post hoc tests demonstrated that muscimol rats showed slightly greater freezing on days $1(P<0.05)$ and $2(P$ $<0.01)$. Crossovers, rearing, and grooming were scored on days 1 and 3 (Fig. 6). A $2 \times 2$ ANOVA showed no effect of drug $\left(F_{(1,13)}=1.6 ; P=0.23\right)$ or day $\left(F_{(1,13)}=4.3 ; P=\right.$ $0.06)$ on crossovers (Fig. 6; top). Nor was there a drug $\left(F_{(1,13)}\right.$ $=3.7 ; P=0.07)$ or day $\left(F_{(1,13)}=1.9 ; P=0.2\right)$ effect on rearing (Fig. 6; bottom). Rats infused with muscimol spent more time grooming than rats infused with saline (Fig. 6; middle) and both groups spent more time grooming on day 3 when compared with day 1 . These observations were confirmed by a main effect of drug $\left(F_{(1,13)}=5.0 ; P<0.05\right)$ and a main effect of day $\left(F_{(1,13)}=5.3 ; P<0.05\right)$ in the ANOVA.

\section{DISCUSSION}

The present data show that infusion of the $\mathrm{GABA}_{\mathrm{A}}$ agonist muscimol into the ventral hippocampus disrupts renewal of Pav- lovian fear memory after extinction. As expected (Corcoran and Maren, 2001, 2004; Hobin et al., 2003; Ji and Maren, 2005), experiment 1 shows that saline-infused rats tested to a CS outside the extinction context freeze more than rats tested inside an extinction context. We now demonstrate that rats tested after muscimol infusion into ventral hippocampus freeze similarly to a CS presented in either context, indicating that the ventral hippocampus, like the dorsal hippocampus, is involved in the contextspecific expression of fear memory after extinction.

One explanation of these results is that ventral hippocampal muscimol infusions produce nonspecific impairments in sensorimotor function that accounts for the observed pattern of results. Experiments 2 and 3 argue against this possibility. Experiment 2 demonstrates that both saline- and muscimoltreated rats can discriminate a context in which they were shocked from one in which they were habituated, although there was a trend towards weaker discrimination in muscimoltreated rats. These data are consistent with previous findings demonstrating that ventral hippocampal muscimol does not disrupt the acquisition and expression of context fear (Maren and Holt, 2004). Experiment 3 demonstrates that the effect of muscimol on context-specific fear memory retrieval is not due to an increase in unconditional locomotor activity. Rats infused
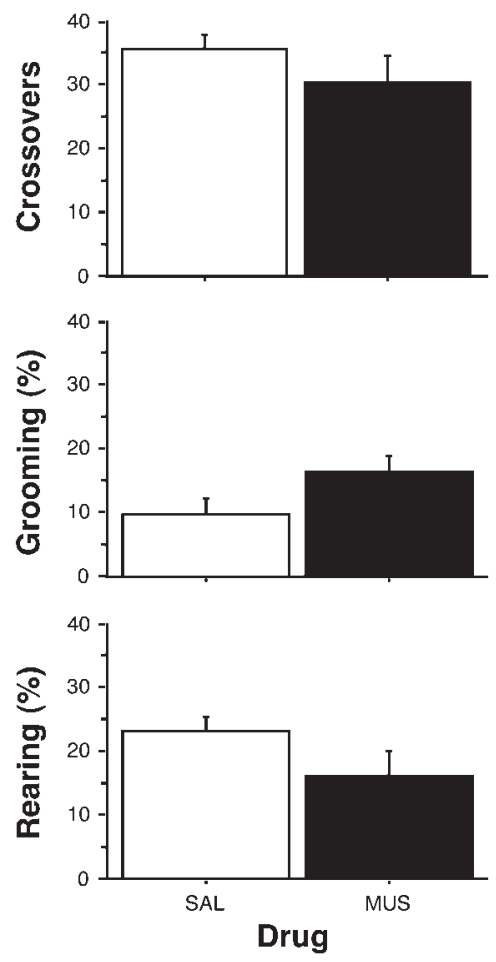

FIGURE 6. Effect of muscimol on crossovers (top), grooming (middle), and rearing (bottom) in experiment 3. Crossovers scored during each minute were summed for the entire session on days 1 and 3 and these summed scores were averaged. The time spent grooming and rearing was averaged across each minute and each day for days 1 and 3. Muscimol had no effect on crossovers or rearing when compared with saline. Muscimol rats spent more time grooming when compared with saline rats. 
with muscimol tended to be less active than saline-treated rats, consistent with results reported by Bast et al. (2001) showing that muscimol infusion into the ventral hippocampus decreases locomotor activity at the dose used in this experiment.

An unexpected finding was that muscimol infusions produced a significant increase in grooming behavior. This increase in grooming may be the result of an anxiolytic effect of ventral hippocampal inactivation. Numerous studies indicate that lesions of the ventral hippocampus result in an attenuation of anxiety as measured by a variety of behavioral tasks (reviewed by Bannerman et al., 2004). While data do not speak directly to the role of the ventral hippocampus in grooming, data do show an increase in measures of social interaction, which include social grooming (Bannerman et al., 2002; McHugh et al., 2004). Both social and self-grooming may be indicative of a decrease in defensive behaviors attributable to a reduction in anxiety.

Collectively, these data show that GABA activity in the ventral hippocampus has an important role in contextual retrieval processes: ventral hippocampal inactivation impaired the contextual modulation of fear memory retrieval while leaving intact the expression of context-CS associations. These data are consistent with data from dorsal hippocampal inactivation studies (Corcoran and Maren, 2001, 2004), and parallel the similar roles for the dorsal and ventral hippocampus in context memory (Matus-Amat et al., 2004; Rudy et al., 2004; Rudy and Matus-Amat, 2005). This begs the question: what, if any, specific role does the ventral hippocampus have in mediating the context-specific retrieval of Pavlovian fear memories? Our data suggest that the ventral hippocampus, like the dorsal hippocampus, may enable contextual retrieval cues to retrieve the appropriate CS association. Indeed, data show that with regard to contextual processing, the dorsal and ventral hippocampus are similar. Extensive evidence suggests that the dorsal hippocampus has a role in encoding contextual information (Anagnostaras et al., 2001; Sanders et al., 2003) and several authors have suggested that the dorsal hippocampus is essential for using contextual information to label and retrieve memories (Hirsh, 1974; Good and Honey, 1991; Maren and Holt, 2000; Rudy and O'Reilly, 2001). Dorsal hippocampal lesions prevent context fear acquisition (Phillips and LeDoux, 1992, 1994; Young et al., 1994; Maren et al., 1997) and expression (Young et al., 1994; Maren et al., 1997; Frankland et al., 1998; Anagnostaras et al., 1999; Trivedi and Coover, 2004). Similarly, ventral hippocampal lesions disrupt context fear acquisition (Maren, 1999; Richmond et al., 1999) and expression (Maren, 1999; Richmond et al., 1999; Maren and Holt, 2004).

In spite of these similarities, ventral hippocampal lesions disrupt tone fear acquisition (Maren, 1999; Richmond et al., 1999; Maren and Holt, 2004) and expression (Maren, 1999; Richmond et al., 1999; Maren and Holt, 2004; Trivedi and Coover, 2004), while dorsal hippocampal lesions typically leave tone conditioning intact (Phillips and LeDoux, 1992; Maren et al., 1997; Anagnostaras et al., 1999; Trivedi and Coover, 2004). So while there appears to be functional overlap in contextual fear conditioning, the auditory conditioning data suggest that there is functional heterogeneity. Indeed, other reports lend support both to the functional distinctions and similarities between dorsal and ventral hippocampus. Some data show that lesions of the dorsal, but not the ventral hippocampus, disrupt performance in spatial tasks (Richmond et al., 1999; Bannerman et al., 2002, 2004), while other data show that both ventral and dorsal hippocampus can support Morris water maze learning (Ferbinteanu and McDonald, 2000; de Hoz et al., 2003). Finally, ventral but not dorsal hippocampal lesions influence measures of unconditioned anxiety (Bannerman et al., 2002, 2003, 2004; McHugh et al., 2004).

Maren and Holt (2004) have argued that the ventral hippocampus may serve as a conduit for the transfer of contextual information between the dorsal hippocampus and the amygdala. By this view, the dorsal hippocampus is necessary for using contextual information to disambiguate the meaning of a CS, whereas the ventral hippocampus is necessary to convey this information to downstream structures, including the amygdala, before it can exert control over fear memory expression. The extensive projections between the ventral hippocampus and the amygdala suggest that it is well situated for this role. However, the present data do not discriminate between this view, and the alternative view that the ventral hippocampus itself has an important role in information processing required for contextual memory retrieval. Because the drug manipulations in the present study were performed prior to retrieval testing, we do not know whether the ventral hippocampus is necessary for encoding context-CS associations during extinction. Recent data suggest that the dorsal hippocampus is not only involved in the context-specific expression of extinction, but also in learning context-CS associations important for this phenomenon (Corcoran et al., in press). If the ventral hippocampus is actively involved in forming context representations necessary for the context-specificity of extinction, then muscimol infusions prior to extinction would be expected to disrupt renewal. Alternatively, if the ventral hippocampus only serves as a relay between the dorsal hippocampus and amygdala, then pre-extinction muscimol infusions should not affect the context-specificity of extinction. Additional experiments are necessary to explore this hypothesis.

The present data reveal that GABA systems in the ventral hippocampus are important for the context-specific expression of Pavlovian fear memories after extinction. In particular, these data suggest that inactivation of the ventral hippocampus with muscimol disrupts the ability of contextual information to disambiguate the meaning of an ambiguous CS. Further research will be necessary to determine the involvement of the ventral hippocampus in encoding the context-CS associations necessary for contextual memory retrieval, and the interaction between the dorsal and ventral hippocampus in this process.

\section{Acknowledgments}

The research was supported by a DOD NDSEG fellowship to JAH. 


\section{REFERENCES}

Anagnostaras SG, Maren S, Fanselow MS. 1999. Temporally graded retrograde amnesia of contextual fear after hippocampal damage in rats: within-subjects examination. J Neurosci 19:1106-1114.

Anagnostaras SG, Gale GD, Fanselow MS. 2001. Hippocampus and contextual fear conditioning: recent controversies and advances. Hippocampus 11:8-17.

Bannerman DM, Deacon RM, Offen S, Friswell J, Grubb M, Rawlins JN. 2002. Double dissociation of function within the hippocampus: spatial memory and hyponeophagia. Behav Neurosci 116:884901.

Bannerman DM, Grubb M, Deacon RM, Yee BK, Feldon J, Rawlins JN. 2003. Ventral hippocampal lesions affect anxiety but not spatial learning. Behav Brain Res 139:197-213.

Bannerman DM, Rawlins JN, McHugh SB, Deacon RM, Yee BK, Bast T, Zhang WN, Pothuizen HH, Feldon J. 2004. Regional dissociations within the hippocampus-memory and anxiety. Neurosci Biobehav Rev 28:273-283.

Bast T, Zhang WN, Feldon J. 2001. The ventral hippocampus and fear conditioning in rats. Different anterograde amnesias of fear after tetrodotoxin inactivation and infusion of the GABA(A) agonist muscimol. Exp Brain Res 139:39-52.

Bouton ME, Bolles RC. 1979. Contextual control of the extinction of conditioned fear. Learn Motiv 10:445-466.

Bouton ME, Mineka S, Barlow DH. 2001. A modern learning theory perspective on the etiology of panic disorder. Psychol Rev 108:4-32.

Corcoran KA, Maren S. 2001. Hippocampal inactivation disrupts contextual retrieval of fear memory after extinction. J Neurosci 21: $1720-1726$

Corcoran KA, Maren S. 2004. Factors regulating the effects of hippocampal inactivation on renewal of conditional fear after extinction. Learn Mem 11:598-603.

Corcoran KA, Desmond TJ, Frey KA, Maren S. 2005. Hippocampal inactivation disrupts the acquisition and contextual encoding of fear extinction. J Neurosci 25:8978-8987.

Davis M, Whalen PJ. 2001. The amygdala: vigilance and emotion. Mol Psychiatry 6:13-34.

Davis M, Walker DL, Myers KM. 2003. Role of the amygdala in fear extinction measured with potentiated startle. Ann N Y Acad Sci 985:218-232.

de Hoz L, Knox J, Morris RG. 2003. Longitudinal axis of the hippocampus: both septal and temporal poles of the hippocampus support water maze spatial learning depending on the training protocol. Hippocampus 13:587-603.

Ferbinteanu J, McDonald AJ. 2000. Dorsal and ventral hippocampus: same or different? Psychobiology 28:314-324.

Frankland PW, Cestari V, Filipkowski RK, McDonald RJ, Silva AJ. 1998. The dorsal hippocampus is essential for context discrimination but not for contextual conditioning. Behav Neurosci 112:863874 .

Good M, Honey RC. 1991. Conditioning and contextual retrieval in hippocampal rats. Behav Neurosci 105:499-509.

Harris JA, Jones ML, Bailey GK, Westbrook RF. 2000. Contextual control over conditioned responding in an extinction paradigm. J Exp Psychol Anim Behav Process 26:174-185.

Hirsh R. 1974. The hippocampus and contextual retrieval of information from memory: a theory. Behav Biol 12:421-444.

Hobin JA, Goosens KA, Maren S. 2003. Context-dependent neuronal activity in the lateral amygdala represents fear memories after extinction. J Neurosci 23:8410-8416.

Holt W, Maren S. 1999. Muscimol inactivation of the dorsal hippocampus impairs contextual retrieval of fear memory. J Neurosci 19: 9054-9062.
Ji J, Maren S. 2005. Electrolytic lesions of the dorsal hippocampus disrupt renewal of conditional fear after extinction. Learn Mem $12: 270-276$.

LeDoux JE. 2000. Emotion circuits in the brain. Annu Rev Neurosci 23:155-184.

Maren S. 1999. Neurotoxic or electrolytic lesions of the ventral subiculum produce deficits in the acquisition and expression of Pavlovian fear conditioning in rats. Behav Neurosci 113:283-290.

Maren S. 2001. Neurobiology of Pavlovian fear conditioning. Annu Rev Neurosci 24:897-931.

Maren S, Fanselow MS. 1995. Synaptic plasticity in the basolateral amygdala induced by hippocampal formation stimulation in vivo. J Neurosci 15:7548-7564.

Maren S, Holt W. 2000. The hippocampus and contextual memory retrieval in Pavlovian conditioning. Behav Brain Res 110:97108

Maren S, Holt WG. 2004. Hippocampus and Pavlovian fear conditioning in rats: muscimol infusions into the ventral, but not dorsal, hippocampus impair the acquisition of conditional freezing to an auditory conditional stimulus. Behav Neurosci 118:97-110.

Maren S, Quirk GJ. 2004. Neuronal signalling of fear memory. Nat Rev Neurosci 5:844-852.

Maren S, Aharonov G, Fanselow MS. 1997. Neurotoxic lesions of the dorsal hippocampus and Pavlovian fear conditioning in rats. Behav Brain Res 88:261-274.

Matus-Amat P, Higgins EA, Barrientos RM, Rudy JW. 2004. The role of the dorsal hippocampus in the acquisition and retrieval of context memory representations. J Neurosci 24:2431-2439.

McHugh SB, Deacon RM, Rawlins JN, Bannerman DM. 2004. Amygdala and ventral hippocampus contribute differentially to mechanisms of fear and anxiety. Behav Neurosci 118:63-78.

O'Reilly RC, Rudy JW. 2001. Conjunctive representations in learning and memory: principles of cortical and hippocampal function. Psychol Rev 108:311-345.

Phillips RG, LeDoux JE. 1992. Differential contribution of amygdala and hippocampus to cued and contextual fear conditioning. Behav Neurosci 106:274-285.

Phillips RG, LeDoux JE. 1994. Lesions of the dorsal hippocampal formation interfere with background but not foreground contextual fear conditioning. Learn Mem 1:34-44.

Pitkanen A. 2000. Connectivity of the rat amygdaloid complex. In: Aggleton JP, editor. The Amygdala. New York: Oxford University Press. p 31-116.

Pitkanen A, Pikkarainen M, Nurminen N, Ylinen A. 2000. Reciprocal connections between the amygdala and the hippocampal formation, perirhinal cortex, and postrhinal cortex in rat. A review. Ann N Y Acad Sci 911:369-391.

Quirk GJ, Gehlert DR. 2003. Inhibition of the amygdala: key to pathological states? Ann N Y Acad Sci 985:263-272.

Richmond MA, Yee BK, Pouzet B, Veenman L, Rawlins JN, Feldon J, Bannerman DM. 1999. Dissociating context and space within the hippocampus: effects of complete, dorsal, and ventral excitotoxic hippocampal lesions on conditioned freezing and spatial learning. Behav Neurosci 113:1189-1203.

Rudy JW, O'Reilly RC. 2001. Conjunctive representations, the hippocampus, and contextual fear conditioning. Cogn Affect Behav Neurosci 1:66-82.

Rudy JW, Matus-Amat P. 2005. The ventral hippocampus supports a memory representation of context and contextual fear conditioning: implications for a unitary function of the hippocampus. Behav Neurosci 119:154-163.

Rudy JW, Barrientos RM, O’Reilly RC. 2002. Hippocampal formation supports conditioning to memory of a context. Behav Neurosci $116: 530-538$.

Rudy JW, Huff NC, Matus-Amat P. 2004. Understanding contextual fear conditioning: insights from a two-process model. Neurosci Biobehav Rev 28:675-685. 
Sanders MJ, Wiltgen BJ, Fanselow MS. 2003. The place of the hippocampus in fear conditioning. Eur J Pharmacol 463:217223.

Sutherland RJ, Rudy JW. 1989. Configural association theory: the role of the hippocampal formation in learning, memory, and amnesia. Psychobiology 17:129-144.

Swanson LW. 1992. Brain maps: structure of the rat brain. New York: Elsevier.

Trivedi MA, Coover GD. 2004. Lesions of the ventral hippocampus, but not the dorsal hippocampus, impair conditioned fear expres- sion and inhibitory avoidance on the elevated T-maze. Neurobiol Learn Mem 81:172-184.

Young SL, Bohenek DL, Fanselow MS. 1994. NMDA processes mediate anterograde amnesia of contextual fear conditioning induced by hippocampal damage: immunization against amnesia by context preexposure. Behav Neurosci 108:19-29.

Zhang WN, Bast T, Feldon J. 2001. The ventral hippocampus and fear conditioning in rats: different anterograde amnesias of fear after infusion of $N$-methyl-D-aspartate or its noncompetitive antagonist MK801 into the ventral hippocampus. Behav Brain Res 126:159-174. 